\title{
Review: a single dose of nasal decongestant reduces congestion in the short term in adults with the common cold; insufficient evidence exists on the effectiveness of repeated doses
}

Taverner D, Latte J, Draper M. Nasal decongestants for the common cold. Cochrane Database Syst Rev 2004;(3):CD001953.

Are nasal decongestants effective for reducing the symptom of nasal congestion in adults and children with the common cold? Are adverse effects associated with use?

\section{METHODS}

Data sources: Cochrane Central Register of Controlled Trials
(Cochrane Library, Issue 1, 2004), Medline (1996 to February
2004), EMBASE/Excerpta Medica (1996 to February 2004),
Current Contents (February 2004), hand searches of review
citations from other references, and contact with known principal
investigators and pharmaceutical companies.
$\begin{aligned} & \text { Study selection and assessment: randomised controlled trials } \\ & \text { (RCTs) in any language that compared topical or oral single } \\ & \text { active nasal decongestants (aqueous spray, drops or dry powder, } \\ & \text { tablets, or capsules) with placebo (>12 patients/group) in adults } \\ & \text { or children who had the common cold (presence of upper } \\ & \text { respiratory tract infection), with onset of symptoms } \leqslant 5 \text { days } \\ & \text { before the start of the study. Exclusion criteria: patients with nasal } \\ & \text { congestion arising from allergic or chronic rhinitis and studies of } \\ & \text { combined treatments or warm, humidified air, steam, and } \\ & \text { aromatic vapours. } \\ & \text { Outcomes: subjective symptom scores for nasal congestion, } \\ & \text { objective measures of nasal airways resistance (assessed using } \\ & \text { rhinomanometry), and adverse events. }\end{aligned}$

\section{MAIN RESULTS}

5 studies (286 adults) met the selection criteria. No studies of children were identified. Nasal decongestants assessed were topical oxymetazoline, oral phenylpropanolamine (norephedrine), and oral pseudoephedrine; all studies used the recommended effective dose of the drug. 4 trials assessed a single dose of nasal decongestant, and 1 trial assessed repeated doses.

Meta-analysis showed that a single dose of decongestant significantly reduced both subjective and objective assessment of nasal congestion (table). In the repeated dose study, nasal decongestants used twice daily over a 5 day period did not differ from placebo for symptom scores (table). Studies did not systematically report data on adverse events.

For correspondence: Dr D Taverner, Internal Medicine, Royal Adelaide Hospital, Adelaide, South Australia, Australia. dtaverne@mail.rah.sa.gov.au Source of funding: Cochrane Acute Respiratory Infections Group, Australia.

\section{CONCLUSIONS}

A single dose of nasal decongestant reduces nasal congestion in the short term in adults with the common cold. Insufficient evidence exists on the effectiveness of repeated doses over several days. No studies of children were identified.

\section{Commentary}

Ithough usually benign, the common cold accounts for substantial
school and job absenteeism and primary care visits. Because
there is no cure or preventive vaccine, treatment is aimed at
symptom control. The systematic review by Taverner et al contributes to
existing evidence on the effectiveness of single agent topical and oral
nasal decongestants. Strengths of the review are the inclusion of studies
in all languages, attention to symptom definition, and use of both
subjective and objective outcome measures.
The conclusions of the review are important for nursing practice
because patients frequently ask for advice on control of cold symptoms.
Based on the evidence from this review, adults can be informed that a
single dose of a topical or oral nasal decongestant may be moderately
effective in reducing congestion, but insufficient evidence exists on the
effectiveness of multiple doses. Parents should be advised that there is no
evidence to support the use of decongestants in children $<12$ years of
age. Simple analgesics (eg, paracetamol), rest, fluids, and information
about the natural history of the common cold may be helpful.
Although adverse effects of decongestant use were not systematically
reported in the reviewed trials, it is important to remind patients that the
accessibility of over the counter nasal decongestants does not
necessarily mean that these products are effective or safe for everyone.
Nasal decongestants should be avoided in patients receiving some types
of antidepressant drugs; patients with hypertension, diabetes, and
coronary artery disease should be counselled to consult their primary
care providers or pharmacists before using decongestants. An example
of the potential for harm is the recent ban, removal, or marketing
restrictions in several countries on the decongestant phenylpropanol-
amine because of evidence linking it with haemorrhagic stroke. 2
Ruth Martin Misener, RN, NP, MN, DOCHN
Dalhousie University School of Nursing
Halifax, Nova Scotia, Canada

Nasal decongestants $v$ placebo for the common cold ${ }^{*}$

\begin{tabular}{llll}
\hline Outcomes & Dosage & Number of studies (n) & Weighted mean difference (95\% Cl) \\
\hline $\begin{array}{l}\text { Subjective assessment of congestion at 2 hours } \\
\text { Subjective assessment of congestion (5 d mean) }\end{array}$ & $\begin{array}{l}\text { Single } \\
\text { Repeated }\end{array}$ & $4(195)$ & $-0.13(-0.19$ to -0.07$)$ \\
\hline & & & $-0.07(-0.21$ to 0.07)† \\
\hline $\begin{array}{l}\text { Objective assessment of congestion } \\
\text { (nasal airways resistance) at 2 hours }\end{array}$ & Single & $4(177)$ & Standardised mean difference (CI) \\
\hline
\end{tabular}

${ }^{*} \mathrm{Cl}$ defined in glossary. Mean differences based on a fixed effects model.

†Not statistically significant. 